\title{
Sensory Input Regulates Spatial and Subtype-Specific Patterns of Neuronal Turnover in the Adult Olfactory Bulb
}

\author{
Masato Sawada, ${ }^{1}$ Naoko Kaneko, ${ }^{1}$ Hiroyuki Inada, ${ }^{2}$ Hiroaki Wake, ${ }^{2,3}$ Yasuko Kato, ${ }^{1}$ Yuchio Yanagawa, ${ }^{3,4}$ \\ Kazuto Kobayashi, ${ }^{5}$ Tomomi Nemoto, ${ }^{3,6,7}$ Junichi Nabekura, ${ }^{2,3,8}$ and Kazunobu Sawamoto ${ }^{1}$ \\ ${ }^{1}$ Department of Developmental and Regenerative Biology, Nagoya City University Graduate School of Medical Sciences, Nagoya 467-8601, Japan, ${ }^{2}$ Division \\ of Homeostatic Development, Department of Developmental Physiology, National Institute for Physiological Sciences, Okazaki 444-8585, Japan, ${ }^{3}$ Core \\ Research for Evolutional Science and Technology, Japan Science and Technology Agency, Saitama 332-0012, Japan, ${ }^{4}$ Department of Genetic and Behavioral \\ Neuroscience, Gunma University Graduate School of Medicine, Maebashi 371-8511, Japan, ${ }^{5}$ Department of Molecular Genetics, Institute of Biomedical \\ Sciences, Fukushima Medical University School of Medicine, Fukushima 960-1295, Japan, ${ }^{6}$ Supportive Center for Brain Research, National Institute for \\ Physiological Science, Okazaki 444-8787, Japan, ${ }^{7}$ Laboratory of Molecular and Cellular Biophysics, Research Institute for Electronic Science, Hokkaido \\ University, Sapporo 001-0020, Japan, and ${ }^{8}$ Department of Physiological Sciences, The Graduate School for Advanced Study (Sokendai), Hayama 240-0198, \\ Japan
}

Throughout life, new neurons are added and old ones eliminated in the adult mouse olfactory bulb. Previous studies suggested that olfactory experience controls the process by which new neurons are integrated into mature circuits. Here we report novel olfactoryexperience-dependent mechanisms of neuronal turnover. Using two-photon laser-scanning microscopy and sensory manipulations in adult live mice, we found that the neuronal turnover was dynamically controlled by olfactory input in a neuronal subtype-specific manner. Olfactory input enhanced this turnover, which was characterized by the reiterated use of the same positions in the glomeruli by new neurons. Our results suggest that olfactory-experience-dependent modification of neuronal turnover confers structural plasticity and stability on the olfactory bulb.

\section{Introduction}

Neurons are continuously added and eliminated, even in the mature brain, throughout life (Alvarez-Buylla and Lim, 2004; Lledo et al., 2006; Zhao et al., 2008). The mechanisms regulating this neuronal turnover, which underlies the plasticity and stability of the adult neural circuitry, are not fully understood, largely because of the difficulty of monitoring neurons over time in living adult mammals.

The adult olfactory bulb (OB), a primary processing center for odor information, provides a powerful model for resolving these fundamental questions (Lledo and Saghatelyan, 2005; Lledo et al.,

Received Jan. 26, 2011; revised May 2, 2011; accepted June 23, 2011.

Author contributions: M.S., N.K., T.N., J.N., and K.S. designed research; M.S., N.K., H.I., H.W., and Y.K. performed research; Y.Y. and K.K. contributed unpublished reagents/analytic tools; M.S., N.K., J.N., and K.S. analyzed data; M.S., N.K., and K.S. wrote the paper.

This work was supported by the Cooperative Study Program of the National Institute for Physiological Sciences, the Ministry of Education, Culture, Sports, Science and Technology, the Japan Society for the Promotion of Science, the Ministry of Health, Labor and Welfare, the Human Frontier Science Program Organization, and the Funding Program for Next Generation of World-Leading Researchers. We thank M. Yamaguchi and A. Alvarez-Buylla for valuable discussions and comments on this manuscript; N. Heintz, C. Gerfen, and the Mutant Mouse Regional Resource Centers for providing the TH-Cre mice; F. Costantini for providing the Rosa26R-CFP mice; RIKEN BRC for providing the TH-GFP mice; A. Miyawaki for providing pCS2-Venus; R. Kageyama, T. Miyamoto, and I. Miyoshi for technical support; and members of the Sawamoto laboratory for discussions. M.S. is a Research Fellow of the Japan Society for the Promotion of Science.

The authors declare no competing financial interests.

Correspondence should be addressed to Dr. Kazunobu Sawamoto, Department of Developmental and Regenerative Biology, Nagoya City University Graduate School of Medical Sciences, 1 Kawasumi, Mizuho-cho, Mizuho-ku, Nagoya, Aichi 467-8601, Japan. E-mail: sawamoto@med.nagoya-cu.ac.jp.

DOI:10.1523/JNEUROSCI.0614-11.2011

Copyright $\odot 2011$ the authors $\quad 0270-6474 / 11 / 3111587-10 \$ 15.00 / 0$
2006). While the OB shows a highly organized laminar structure, neurons within the $\mathrm{OB}$ are intensively replaced (Ninkovic et al., 2007; Imayoshi et al., 2008). Olfactory interneurons are continuously generated in the subventricular zone (SVZ) and migrate into the $\mathrm{OB}$, where they differentiate into the granule cells (GCs) and periglomerular cells (PGCs) (Altman, 1969; Luskin, 1993; Lois and Alvarez-Buylla, 1994), which are involved in the maintenance of the OB structure (Imayoshi et al., 2008) and various olfactory functions (Gheusi et al., 2000; Mak et al., 2007; BretonProvencher et al., 2009; Moreno et al., 2009). Previous studies suggested that the survival of these OB neurons depends on olfactory input (Petreanu and Alvarez-Buylla, 2002; Rochefort et al., 2002; Yamaguchi and Mori, 2005). Recent progress using two-photon laser-scanning microscopy (2PLSM) (Denk et al., 1990) has led to the discovery of sensory-experience-dependent synaptic changes involving dendritic spine dynamics in the adult brain (Trachtenberg et al., 2002; Holtmaat et al., 2006; Livneh et al., 2009; Yang et al., 2009). This imaging technique is also useful for the turnover analysis of PGCs because of their location in the surface layer of the OB (Mizrahi et al., 2006), providing a unique model for examining the dynamics of added and eliminated neurons simultaneously in vivo.

In this study, we investigated the mechanisms of PGC turnover directly in vivo, using a three-time-point 2PLSM imaging technique. Our results clearly demonstrate that the dynamics of neuronal addition and elimination are spatiotemporally controlled in a neuronal-subtype-specific and olfactory-inputdependent manner. 


\section{Materials and Methods}

Animals and BrdU labeling. For two-photon imaging, adult (P56-P112) male VGAT-Venus line \#39 (Wang et al., 2009), GAD67-GFP (Tamamaki et al., 2003), and TH-GFP (Sawamoto et al., 2001; Matsushita et al., 2002) mice were used. In addition to these transgenic mice, adult (P56-P62) male wild-type (C57BL/6J, purchased from SLC) and TH-Cre;Rosa26RCFP (Srinivas et al., 2001; Gong et al., 2007) mice were used for immunohistological studies. Mice were injected with bromodeoxyuridine (BrdU, $50 \mathrm{mg} / \mathrm{kg}$, Sigma) in PBS twice with a $2 \mathrm{~h}$ interval. Among the transgenic mouse lines used in this study, there were no differences in the neurogenesis (the production, migration, or survival of the progenitors of olfactory interneurons) in the SVZ-OB or in the response to olfactory manipulations (data not shown). All the experiments on live animals were performed in accordance with the guidelines and regulations of Nagoya City University and the National Institutes for Natural Sciences.

Thinned-skull surgery and two-photon imaging. In vivo two-photon imaging of fluorescent-protein-labeled PGCs was performed as reported previously (Mizrahi et al., 2006) with modifications. Mice were anesthetized with an injection of a ketamine/xylazine mixture $(130 \mathrm{mg} / \mathrm{kg}$ and 10 $\mathrm{mg} / \mathrm{kg}$, respectively) and the head was immobilized with ear bars on a stereotactic stage. The skull over the OB was carefully thinned using a high-speed drill (Fine Science Tools) and a surgical blade (BD Biosciences) to a $20-30 \mu \mathrm{m}$ thickness under a stereomicroscope as previously described (Wake et al., 2009). We confirmed that these procedures did not cause detectable immune reactions during the experimental period, as previously reported (Xu et al., 2007). For the second and third imaging sessions, the skull over the $\mathrm{OB}$ was carefully rethinned with a surgical blade to acquire high-resolution images. The body temperature of the mouse was maintained $37^{\circ} \mathrm{C}$ using a heating pad throughout the surgery and subsequent imaging $(\sim 2-3 \mathrm{~h})$. After imaging, the scalp was sutured immediately. The mice were returned to the home cage and individually housed until the next imaging.

Venus + or GFP+ PGCs were imaged under a custom-built twophoton laser-scanning microscope and mode-locked laser system at 950 nm (Mai Tai HP, Spectra Physics) through a water-immersion objective lens (25×, NA1.05) (Olympus). Scanning and image acquisition were performed with Fluoview software (Olympus). The average power delivered to the brain was $<30 \mathrm{~mW}$. Image stacks $(512 \times 512$ pixels, $0.33 \mu \mathrm{m}$ per pixel, $2 \mu \mathrm{m} z$-step size) were usually acquired from the pial surface to a depth of $90-150 \mu \mathrm{m}$. In the time-lapse imaging, the images of PGCs were captured at $15 \mathrm{~min}$ intervals. In the three-time-point imaging at 4 week intervals, two to three different regions of the glomerular layer per mouse were imaged for the analyses (VGAT-Venus mice, 41 regions $[n=$ 17 animals]; GAD67-GFP mice, 10 regions [ $n=5$ animals]; TH-GFP mice, 32 regions $[n=15$ animals]). Same regions could be repeatedly identified based on the blood vessel map of the dorsal surface of the OB and the glomerular patterns.

Two-photon laser ablation. Targeted GFP+ PGCs were magnified and irradiated by a two-photon laser at $950 \mathrm{~nm}$ until the GFP could not be detected $(\sim 30-120 \mathrm{~s})$. The average power delivered to the brain was 50 $\mathrm{mW}$. A small number of PGCs ( $1-4$ cells per glomerulus) was eliminated to study the fates of the resulting empty positions independently. Elimination of the targeted PGCs was confirmed by imaging these areas immediately after the laser ablation and again $2-5 \mathrm{~d}$ later. To confirm the complete ablation of these cells, "shadow imaging" (Kitamura et al., 2008) was performed. Briefly, $2 \mathrm{~d}$ after the laser ablation, the skull over the OB was partially removed, and $50 \mu \mathrm{l}$ of $3 \mathrm{~mm}$ sulforhodamine 101 (SR101) (Sigma) was applied to the exposed region. Immediately afterward, images of the area were acquired, in which the SR101-positive extracellular region and SR101-negative spherical areas ("shadows" of cell bodies) clearly showed that the disappearance of GFP expression was due to the elimination of cell bodies ( $100 \pm 0 \%, n=5$ animals), and not to the laser bleaching of the GFP fluorescence.

Data analysis for two-photon imaging. The acquired raw images were $z$-stacked and projected, using ImageJ software for analysis. Venus + or GFP+ PGCs in each imaging session were identified and numbered using both Fluoview $z$-stack movies and projected images. Mice from which high-resolution images could be acquired throughout the experi- mental period were used for the analyses. For the VGAT-Venus mice, the number of identified PGCs was 1603 for the control, 727 for the occlusion, and 1113 for the reopening ( $n=8,4$, and 5 animals, respectively). For the GAD67-GFP mice ( $n=5$ animals), 847 PGCs were identified. For the TH-GFP mice, the number of identified PGCs was 737 for the control, 470 for the naris occlusion and reopening, 868 for the laser ablation, and 344 for the laser ablation and naris occlusion $(n=3,3,5$, and 4 animals, respectively). The PGCs identified in the repeated imaging sessions were classified as "stable," "added," or "lost," as reported previously (Mizrahi et al., 2006). The populations of added and lost PGCs after 4 weeks are shown as the percentage relative to the total number of identified PGCs on day 0 (for analysis of days $0-28$ ) or day 28 (for analysis of days $28-56$ ). For the analyses of the spatial characteristics of PGC turnover (see Figs. 2, 4), the territory of a lost PGC was defined as a spherical region with a $5 \mu \mathrm{m}$ radius from the center of a PGC that had been lost. When a newly added PGC was located inside the territory of a lost PGC, it was classified as a "replacement" cell. When it was located outside the territory of a lost PGC, it was classified as a "random" cell. The frequency of replacement cell addition is shown as the percentage relative to the total number of added PGCs. When a position that had lost a PGC was filled by new one, the position was classified as "filled." Positions that had lost a PGC but were not occupied by replacement cells were classified as "unfilled." The frequency of a position being "filled" is shown as the percentage relative to the total number of the positions that had lost PGCs.

Reversible olfactory deprivation. To regulate olfactory input reversibly, naris occlusion plugs (Cummings et al., 1997) were used. These plugs were made of polyethylene tubing (SP35, Natume), silk thread (4-0, Akiyama), and a piece of Japanese female hair to be used as a pull string. The length of the plug was adjusted to $6 \mathrm{~mm}$. The mice were anesthetized with an injection of sodium pentobarbital $(60 \mathrm{mg} / \mathrm{kg})$, and the plug was coated with petroleum jelly and inserted into the left nasal cavity. To reopen the naris, the plug was removed by pulling on the hair using forceps under anesthesia.

Immunohistochemistry. Brains were fixed by transcardiac perfusion with $4 \%$ paraformaldehyde in $0.1 \mathrm{M}$ phosphate buffer, postfixed overnight in the same fixative, and $50-\mu \mathrm{m}$-thick floating coronal sections were prepared using a vibratome as reported previously (Sawamoto et al., 2006; Kaneko et al., 2010). The sections were incubated for $40 \mathrm{~min}$ in $1 \%$ $\mathrm{H}_{2} \mathrm{O}_{2}$ in PBS, 30 min in blocking solution (0.5\% TNB (PerkinElmer) and $0.1 \%$ Triton $\mathrm{X}-100$ in PBS), overnight at $4^{\circ} \mathrm{C}$ with the primary antibodies, and $2 \mathrm{~h}$ at room temperature with biotin-, HRP-, Fluorescein-, or AlexaFluor-conjugated secondary antibodies (1:500, Invitrogen) in the same solution. The signals were amplified with biotin-conjugated antibodies and the Vectastain Elite ABC kit (Vector Laboratories), and visualized using the TSA Fluorescence Systems (PerkinElmer) or diaminobenzidine tetrahydrochloride (DAB, Wako). In the case of BrdU staining, the sections were pretreated with $2 \mathrm{~N} \mathrm{HCl}$ for 40 min at $60^{\circ} \mathrm{C}$ before $\mathrm{H}_{2} \mathrm{O}_{2}$ incubation. The following primary antibodies were used: rat anti-BrdU antibody, 1:100 (Abcam); mouse anti-calbindin (CB) monoclonal antibody (IgG), 1:3000 (Sigma); mouse anti-calretinin (CR) monoclonal antibody (IgG), 1:3000 (Millipore Bioscience Research Reagents); rabbit anti-cleaved caspase-3 antibody, 1:200 (Cell Signaling Technology); rat anti-dopamine transporter (DAT) antibody, 1:100 (Abcam); goat antidoublecortin (Dcx) antibody, 1:100 (Santa Cruz Biotechnology); mouse anti-glutamic acid decarboxylase 67 (GAD67) monoclonal antibody (IgG), 1:800 (Millipore Bioscience Research Reagents); rabbit anti-GFP antibody, 1:100 (MBL); chicken anti-GFP antibody, 1:100 (Aves Labs); rabbit anti-Ki67 antibody, 1:500 (Novocastra); rabbit anti-Pax6 antibody, 1:400 (Covance); mouse anti-parvalbumin (PV) monoclonal antibody (IgG), 1:2000 (Sigma); rabbit anti-single-stranded DNA (ssDNA) antibody, 1:1600 (Dako); and mouse anti-tyrosine hydroxylase (TH) monoclonal antibody (IgG), 1:1600 (Millipore Bioscience Research Reagents). Nuclei were stained with Hoechst33342 (Sigma).

Quantification analysis. To characterize the PGCs, the colocalization of the signals in the glomerular layer was confirmed by scanning at $1 \mu \mathrm{m}$ intervals. The scanning was performed using a confocal laser-scanning microscope, LSM 710 or LSM5 Pascal (Carl Zeiss) with a waterimmersion objective lens $(40 \times)$. The double-positive cells in the glomer- 

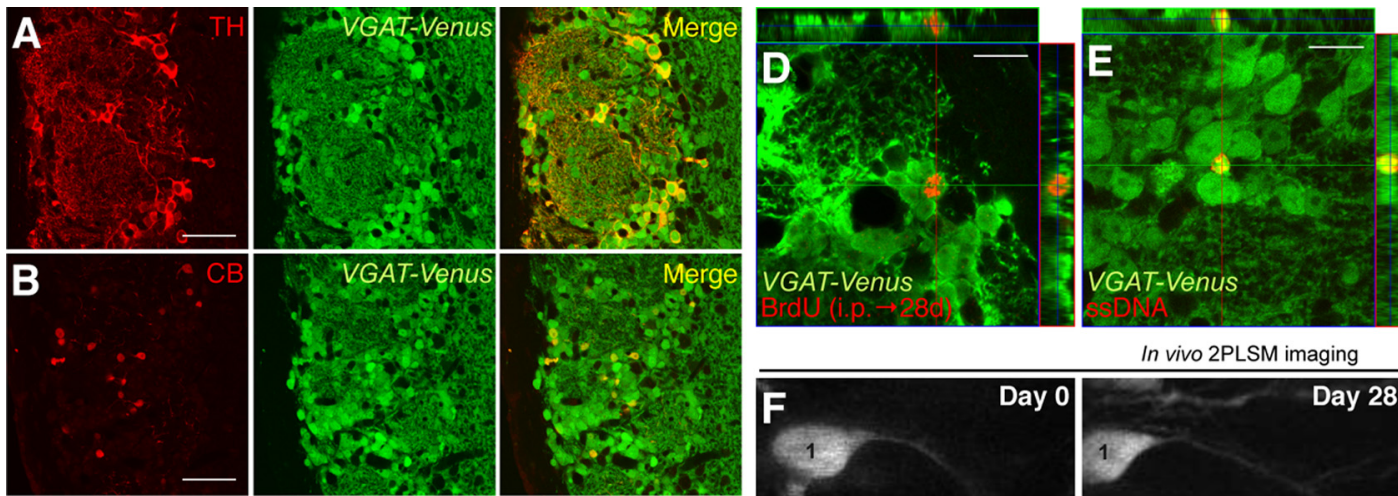

In vivo $2 \mathrm{PLSM}$ imaging
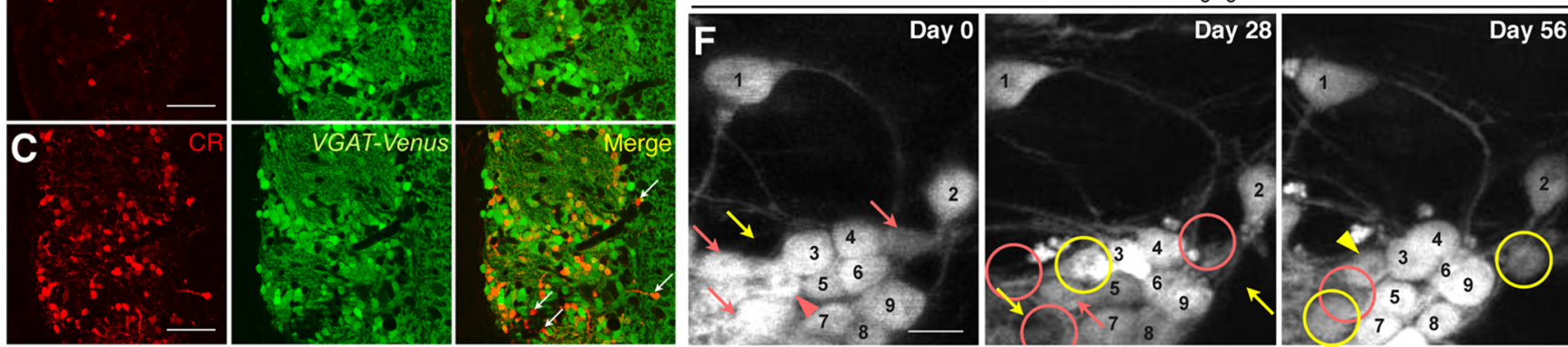

Figure 1. In vivo three-time-point 2PLSM imaging of PGC turnover in VGAT-Venus mice. A-C, Coronal sections of the olfactory glomerular layer in VGAT-Venus mice stained for PGC subtypespecific markers TH, CB, and CR (red). All the TH + and CB + PGCs were labeled with Venus ( $\boldsymbol{A}$ and $\boldsymbol{B}$, respectively, green), whereas a small population of CR + PGCS was not labeled with Venus ( $\boldsymbol{C}$, white arrows). See also Table 1. $\boldsymbol{D}, \boldsymbol{E}$, Detection of the addition $(\boldsymbol{D})$ and apoptosis $(\boldsymbol{E})$ of Venus + PGCs using immunohistochemistry. Mice were injected with BrdU to label neuronal progenitors. The analysis was performed 28 d later, when the labeled cells had matured. Representative images of Venus-expressing BrdU+ $(\boldsymbol{D}$, red) and ssDNA+ apoptotic ( $\boldsymbol{E}$, red) PGCs (D, $\boldsymbol{E}$, green) are shown. $\boldsymbol{F}$, In vivo imaging of PGC turnover in VGAT-Venus mice under normal physiological conditions on days 0,28 , and 56 . PGCs labeled with a pink arrow had disappeared (pink circles, lost population) at the next imaging session. The PGC labeled with a pink arrowhead observed on day 0 had been lost on day 56 (pink circle). At the positions indicated by a yellow arrow, new added PGCs were observed 28 d later (yellow circles, added population). The PGC labeled with a yellow arrowhead was identified on day 28 and still observed on day 56 . PGCs stably observed throughout the experimental period are numbered. Scale bars: $\boldsymbol{A}-\boldsymbol{C}, 50 \mu \mathrm{m} ; \boldsymbol{D}-\boldsymbol{F}, 10 \mu \mathrm{m}$.

Table 1. Expression patterns of fluorescent proteins in the glomerular layer in transgenic mouse lines used in this study

\begin{tabular}{|c|c|c|c|c|c|c|}
\hline \multirow[b]{2}{*}{ Markers } & \multicolumn{2}{|l|}{ VGAT-Venus } & \multicolumn{2}{|c|}{ TH-Cre;Rosa26R-CFP } & \multicolumn{2}{|l|}{ TH-GFP } \\
\hline & Marker $+[\%]$ & Venus $+[\%]$ & Marker + [\%] & $\mathrm{CFP}+[\%]$ & Marker $+[\%]$ & $\mathrm{GFP}+[\%]$ \\
\hline $\mathrm{TH}$ & $\begin{array}{l}20.0 \pm 0.3 \\
(n=2120)\end{array}$ & $\begin{array}{l}98.1 \pm 0.7 \\
(n=432)\end{array}$ & $\begin{array}{l}72.1 \pm 1.5 \\
(n=1571)\end{array}$ & $\begin{array}{l}64.5 \pm 1.1 \\
(n=1762)\end{array}$ & $\begin{array}{l}82.7 \pm 1.4 \\
(n=804)\end{array}$ & $\begin{array}{l}98.1 \pm 0.6 \\
(n=676)\end{array}$ \\
\hline$C B$ & $\begin{array}{l}15.0 \pm 0.3 \\
(n=2274)\end{array}$ & $\begin{array}{l}98.9 \pm 0.2 \\
(n=344)\end{array}$ & $\begin{array}{c}0 \pm 0 \\
(n=713)\end{array}$ & $\begin{array}{c}0 \pm 0 \\
(n=404)\end{array}$ & $\begin{array}{l}0.27 \pm 0.1 \\
(n=760)\end{array}$ & $\begin{array}{l}0.57 \pm 0.3 \\
(n=350)\end{array}$ \\
\hline$C R$ & $\begin{array}{l}34.5 \pm 3.2 \\
(n=1142)\end{array}$ & $\begin{array}{l}79.5 \pm 3.9 \\
(n=495)\end{array}$ & $\begin{array}{l}0.13 \pm 0.1 \\
(n=763)\end{array}$ & $\begin{array}{l}0.05 \pm 0.1 \\
(n=1943)\end{array}$ & $\begin{array}{c}0 \pm 0 \\
(n=368)\end{array}$ & $\begin{array}{c}0 \pm 0 \\
(n=934)\end{array}$ \\
\hline GAD67 & $\begin{array}{l}99.4 \pm 0.2 \\
(n=1166)\end{array}$ & $\begin{array}{l}99.2 \pm 0.2 \\
(n=1169)\end{array}$ & $\begin{array}{l}98.5 \pm 0.03 \\
(n=783)\end{array}$ & $\begin{array}{l}19.0 \pm 0.2 \\
(n=4055)\end{array}$ & $\begin{array}{l}95.1 \pm 0.7 \\
(n=362)\end{array}$ & $\begin{array}{l}22.9 \pm 1.2 \\
(n=1508)\end{array}$ \\
\hline
\end{tabular}

The table shows the percentage of fluorescently-labeled PGCs that expressed TH, CB, CR, or the GABAergic neuron marker, GAD67 (Marker + [\%]) and the percentage of PGCs expressing each neuronal marker that also expressed a fluorescent protein (Venus + , CFP +, or GFP + [\%]). Both TH - /CFP + cells in TH-Cre;Rosa26R-CFP and TH - /GFP + cells in TH-GFP mice express Pax6 (100 $\pm 0 \%$ and $95.7 \pm 0.8 \%$, respectively), which is an early marker for DAergic PGC differentiation (Hack et al., 2005; Kohwi et al., 2005; Haba et al., 2009), but not CB or CR, suggesting that they are immature DAergic PGCs. " $n$ " indicates the number of cells (from three animals) analyzed here.

ular layer were counted. To quantify the CFP+ and DAT+ DAergic PGCs in the TH-Cre;Rosa26R-CFP mice, the cells in the glomerular layer were counted using a Stereo Investigator system (MBF Bioscience), because they were densely populated in the OB. For the quantification of $\mathrm{BrdU}+, \mathrm{Ki} 67+$, and ssDNA+ cells, the images of these cells were acquired using a fluorescence microscope, BX51 (Olympus), and a CCD camera, DP71 (Olympus). In all the immunohistological analyses, the actual number of cells in every sixth $50-\mu \mathrm{m}$-thick coronal section was counted, and then the total number was estimated by multiplying the sum of the counted cells by six.

Statistics. The data obtained in this study are presented as the mean \pm SEM. Comparisons between two groups were analyzed by the paired $t$ test, unpaired $t$ test, or the nonparametric Mann-Whitney $U$ test. For comparisons among multiple groups, the data were analyzed by repeated-measure ANOVA, followed by the post hoc Tukey-Kramer test or Scheffe's $F$ test. Differences were regarded as statistically significant when $p<0.05$.

\section{Results}

Olfactory input promotes the reiterated use of the same positions in the glomeruli by new PGCs

To observe the turnover dynamics of the entire PGC population under 2PLSM, we used adult VGAT-Venus mice, in which almost all the PGCs are labeled with Venus under the vesicular GABA transporter gene promoter (Wang et al., 2009) (Fig. 1 $A-C$; Table $1)$. In the glomerular layer of the $\mathrm{OB}, 91.7 \pm 1.6 \%$ of $\mathrm{BrdU}+$ newly added cells and $77.9 \pm 1.6 \%$ of ssDNA + apoptotic cells expressed Venus (Fig. 1D,E). By comparing the Venus+ cell bodies between two consecutive images (4 week intervals), the PGCs were categorized as stable, added, or lost, as reported previously (Mizrahi et al., 2006) (Fig. $1 F$ ). The added and lost PGC populations represented $\sim 6 \%$ and $4 \%$ of the total PGCs per month, respectively, on days $0-28$ (Fig. $2 \mathrm{D}$, control) and 28-56 (Fig. 2 E, control). Most (>90\%) of the PGCs "lost" between the days 28 and 56 were observed at the (newly unoccupied) positions on day 0 (Fig. $1 F$, day 0 , pink arrowhead), indicating that the missing cells represent the death of mature PGCs. On the other hand, the rest $(9.4 \pm 4.8 \%)$ of the vacant positions were already vacant on day 0 , which accounts for $0.28 \%(=3.0 \%$ [lost population on days $28-56$, Fig. $2 E$, control] $\times 9.4 \%$ ) of Venus + PGCs, suggesting that these positions may be occupied temporarily by migrating cells or by immature cells that are eliminated during the selection stage (Yamaguchi and Mori, 2005). To ex- 
A

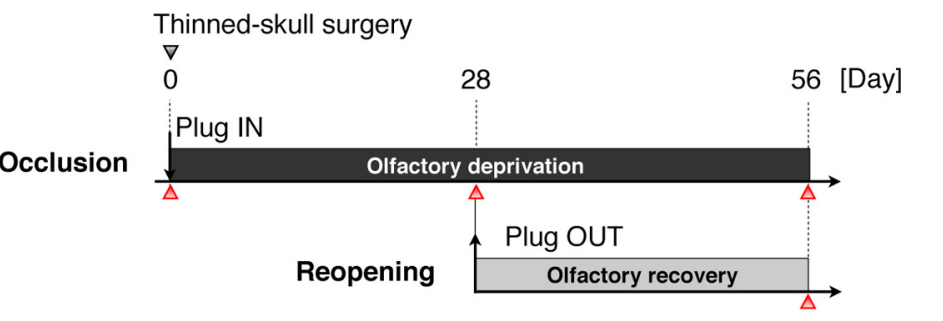

$\Delta$ : in vivo two-photon imaging
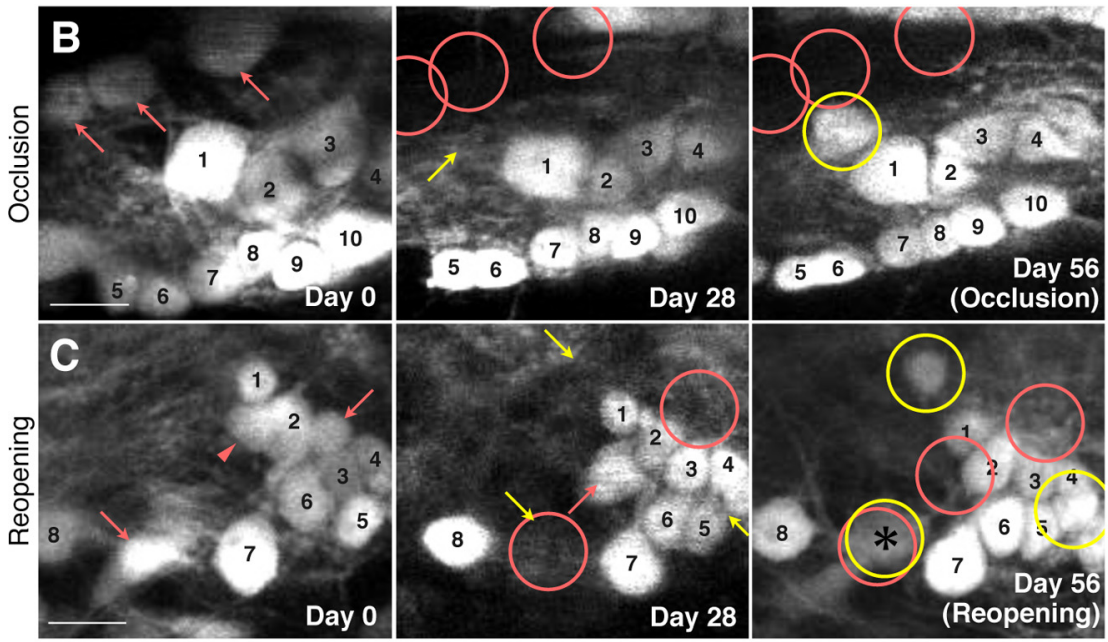

$\mathbf{F}$
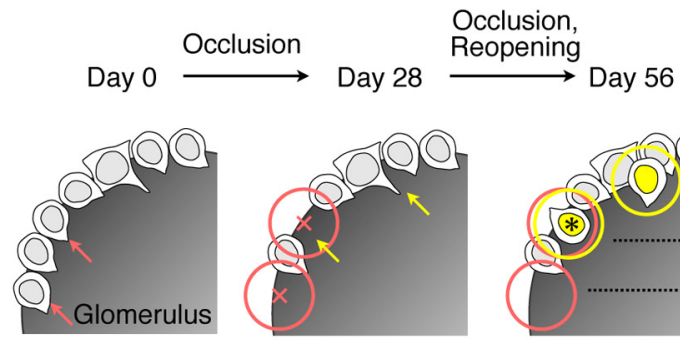

Classification

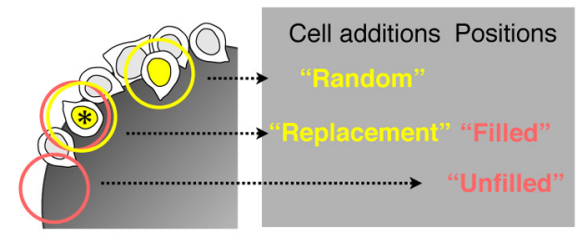

D

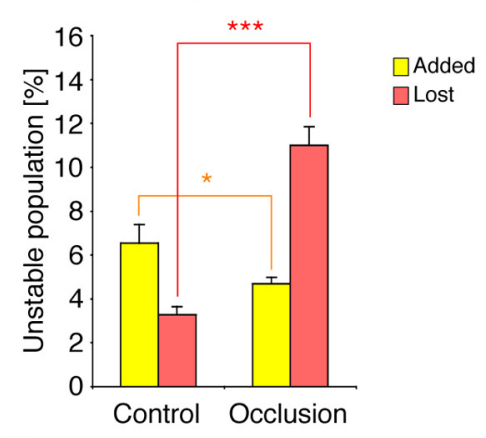

E

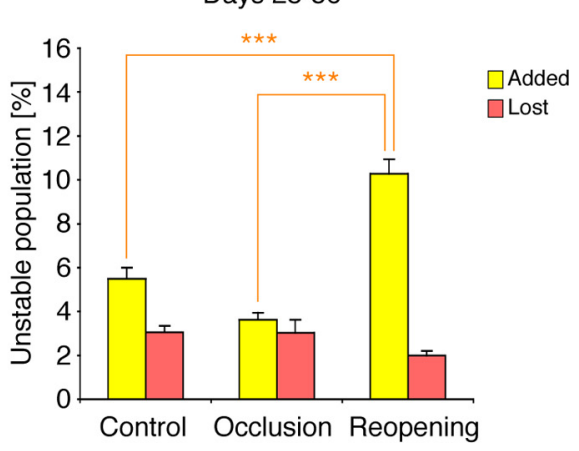

G

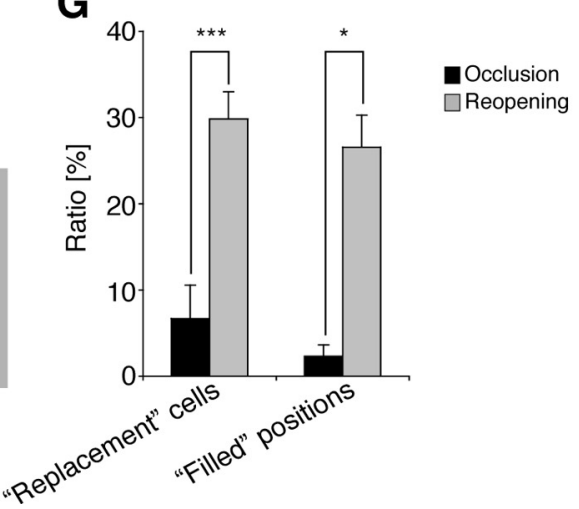

Figure 2. Olfactory-input-dependent reiterated use of the same positions in the glomeruli by new PGCS. $A$, Experimental design. $B, C$, Representative in vivo images showing the patterns of $\mathrm{PGC}$ addition after naris occlusion and reopening in VGAT-Venus mice. Sequential images on days 0,28 , and 56 clearly show the stable (numbered), lost (pink arrows and circles), and added (yellow arrows and circles) PGCs in these areas. Note that the "replacement" cell (black asterisk, see $\boldsymbol{F}$ ) was observed only after naris reopening in these areas (C). The PGC labeled with a pink arrowhead in $\boldsymbol{C}$ had been lost on day 56. D, Percentage of total identified PGCs that was added or lost during the 4 week naris occlusion (days 0 -28). Compared with the control group, in the 4 week naris occlusion group, the population of added PGCs was significantly decreased, whereas that of the lost PGCS was increased ( $\left.{ }^{*} p<0.05,{ }^{* * *} p<0.000001\right)$. E, Percentage of total identified PGCs that was added or lost after naris reopening (days $28-56$ ). Naris reopening significantly increased the population of added PGCs compared with the control and occlusion groups $\left({ }^{* * *} p<0.0001\right) . F$, Classification of new PGC additions and the positions that had lost PGCS. PGCs labeled with pink arrows were eliminated during the 4 week naris occlusion $(\boldsymbol{B}, \boldsymbol{C}, \boldsymbol{F})$. Of the newly added PGCS observed on day 56 , the replacement cells are labeled with a black asterisk. The "filled" positions on day 56 indicate positions where lost cells were replaced by new PGCs (black asterisk). The pink circles indicate the territory of lost PGCS $(\boldsymbol{B}, \boldsymbol{C}, \boldsymbol{F}) . \mathbf{G}$, Quantification on day 56 of the replacement cell additions and the filled positions. The percentages of replacement cells and of filled positions were strikingly increased ( ${ }^{*} p<$ $\left.0.05,{ }^{* * *} p<0.005\right)$ by naris reopening. Scale bars: $10 \mu \mathrm{m}$. The data are presented as the mean \pm SEM.

amine the proportion of migrating cells in the "lost" population in the glomerular layer, we stained OB sections with an anti-Dcx antibody. Of the Dcx $+/$ Venus + PGCs $(2.0 \pm 0.2 \%$ of the Venus+ PGCs), only $5.9 \%$ showed the bipolar, migratory morphology, indicating that $0.12 \%(=2.0 \% \times 5.9 \%)$ of the Venus + PGCs were migrating. Thus, these results indicate that $4 \%(=9.4 \% \times$ $(0.12 \%$ [migrating cells] $/ 0.28 \%$ [migrating and eliminated immature cells])) of the "lost" population could be accounted for by migrating PGCs. Similar turnover rates were observed using another PGC reporter line GAD67-GFP, which expresses GFP under the GAD67 gene promoter (Tamamaki et al., 2003) (added population on days $0-28,6.5 \pm 0.5 \%$; lost population on days $0-28,4.7 \pm 0.7 \%$; added population on days $28-56,7.1 \pm 1.2 \%$; lost population on days $28-56,4.1 \pm 0.7 \% ; n=5$ animals). These results showed that the turnover of GABAergic PGCs could be observed by this imaging method.

To investigate the effects of olfactory experience on the dynamics of PGC turnover in live animals, we imaged the same PGCs three times: before blocking the olfactory input with a nasal occlusion plug (Cummings et al., 1997) (day 0), after $28 \mathrm{~d}$ of occlusion (day 28), and again $28 \mathrm{~d}$ after the plug was removed (day 56) (Fig. 2A-E). The naris reopening did not affect the dis- 

Table 2. Distribution of BrdU + cells in the SVZ, RMS, and OB of the naris-occluded
and naris-reopened hemispheres

\begin{tabular}{|c|c|c|c|c|c|}
\hline \multirow{2}{*}{$\begin{array}{l}\text { Time after BrdU } \\
\text { injection and } \\
\text { naris reopening }\end{array}$} & \multicolumn{3}{|l|}{$O B$} & \multirow[b]{2}{*}{ RMS } & \multirow[b]{2}{*}{ SVZ } \\
\hline & $\mathrm{GL}$ & EPL & $\mathrm{GCL}$ & & \\
\hline \multicolumn{6}{|l|}{$1 \mathrm{~h}$} \\
\hline Control & $130 \pm 19$ & $94 \pm 8$ & $366 \pm 30$ & $1844 \pm 45$ & $6920 \pm 355$ \\
\hline Occlusion & $96 \pm 12$ & $64 \pm 13$ & $322 \pm 11$ & $1838 \pm 191$ & $6830 \pm 237$ \\
\hline \multicolumn{6}{|l|}{1 week } \\
\hline Occlusion & $644 \pm 132$ & $228 \pm 28$ & $5624 \pm 567$ & $7226 \pm 187$ & $2174 \pm 132$ \\
\hline Reopening & $586 \pm 88$ & $212 \pm 7$ & $7228 \pm 575$ & $7870 \pm 375$ & $2230 \pm 245$ \\
\hline \multicolumn{6}{|l|}{4 weeks } \\
\hline Occlusion & $624 \pm 76$ & $120 \pm 30$ & $5558 \pm 400$ & $50 \pm 12$ & $77 \pm 17$ \\
\hline Reopening & $931 \pm 53^{*}$ & $89 \pm 8$ & $7376 \pm 473^{*}$ & $45 \pm 10$ & $84 \pm 11$ \\
\hline
\end{tabular}

After 4 week naris occlusion, mice were injected with BrdU and the nasal plug was removed. Number of BrdU + cells in the SVZ, RMS, and three OB layers (GL, EPL, and GCL) was counted $1 \mathrm{~h}$, 1 week, and 4 weeks after BrdU injection. There was no significant difference in the number of BrdU + proliferating cells in each region between the narisoccluded and control hemispheres ( $1 \mathrm{~h})$. One week after BrdU injection, neuronal progenitors in the SVZ and RMS that had incorporated BrdU migrated toward the $O B$, resulting in a wide distribution of $\mathrm{BrdU}+$ cells along the SVZ-OB pathway. Naris reopening did not affect the distribution of BrdU + cells in the SVZ-OB (1 week). Four weeks after BrdU injection, we quantified the surviving BrdU + cells in the $\mathrm{GCL}$ and $\mathrm{GL}$ layers of the $\mathrm{OB}$. Naris reopening increased the number of BrdU + cells in these layers ( 4 weeks, $n=4$ animals in each condition; ${ }^{*} p<$ 0.05 , unpaired $t$ test).

tribution of BrdU-labeled cells in the SVZ, rostral migratory stream (RMS), or core of the OB 1 h or 1 week after BrdU injection (Table 2), suggesting that the olfactory input did not affect the production and migration of the progenitors of the olfactory interneurons. Consistently, the naris occlusion significantly decreased the number of newly added PGCs (Fig. $2 B-D)(n=8$ control, and $n=9$ occlusion; unpaired $t$ test) and transiently increased the number of "lost" PGCs (Fig. $2 B-E$ ) (Mann-Whitney $U$ test). By reopening the naris after 4 weeks of occlusion, the "added" PGC population was increased by two and three times, respectively, over the added population in the control and occlusion animals (Fig. $2 B, C, E)(n=8$ control, $n=4$ occlusion, and $n=5$ reopening; repeated-measure ANOVA followed by Scheffé's $F$ test), which was consistent with our finding that naris reopening increased the number of BrdU-labeled cells in the glomerular and granule cell layer 4 weeks after BrdU injection (Table 2). These observations of PGC turnover in live animals demonstrated that olfactory input increases the survival ratio of PGCs.

Despite such an extensive cell turnover (Fig. $2 B-E$ ), the adult $\mathrm{OB}$ continuously displays a highly regular pattern of glomeruli, within which new PGCs are located in the superficial areas, suggesting that an underlying mechanism controls the location of the newly added PGCs. In the three-time-point imaging, the fates of newly added PGCs and the positions that had lost PGCs, which were both identified and recorded in the second session, could be reexamined in the third session. Using this technique in combination with olfactory manipulation, we investigated whether positions that were previously occupied by PGCs would be occupied by newly added ones. The naris was occluded for 4 weeks to enhance the loss of PGCs (Fig. 2D). The "territory of a lost PGC" was defined as a spherical region with a $5 \mu \mathrm{m}$ radius from the center of a lost PGC (Fig. $2 B, C, F$, pink circles). We classified the observed new PGCs on day 56 into two groups: those added in the territory of a lost PGC, thereby replacing a cell in a previously occupied position ("replacement" cells) and those inserted elsewhere in the glomerular layer ("random" cells) (Fig. 2 F). We also classified the positions that had lost PGCs on day 28 into two groups: those filled by new PGCs on day 56 ("filled" positions) and those not filled at this time point ("unfilled" positions) (Fig. $2 F)$. Under normal physiological conditions, the percentage of new "replacement" cells was $10.5 \pm 3.8 \%$, and the percentage of empty positions that became "filled" was $21.2 \pm 9.3 \%$. Interestingly, after the massive neuronal loss caused by the 4 week naris occlusion, naris reopening strikingly increased the percentage of added PGCs, classified according to the percentage of replacement cells (Fig. $2 B, C, G$ ) (occlusion, $6.7 \pm 3.9 \%, n=4$ animals; reopening, $29.8 \pm 3.2 \%, n=5$ animals; unpaired $t$ test) and of filled positions (Fig. $2 B, C, G$ ) (occlusion, $2.3 \pm 1.3 \%, n=4$ animals; reopening, $26.6 \pm 3.7 \%, n=5$ animals; Mann-Whitney $U$ test), indicating that olfactory input enhanced the reiterated use of the same positions in glomeruli by new PGCs.

\section{Olfactory input promotes survival of the DAergic subtype of PGCs}

PGCs consist of several chemically nonoverlapping subtypes, including $\mathrm{CB}+, \mathrm{CR}+$, and $\mathrm{TH}+$ neurons (Kosaka and Kosaka, 2007), all of which make inhibitory synapses on olfactory sensory neurons and projection neurons (mitral/tufted cells) inside the glomeruli, to modulate olfactory stimulation. The majority of adult-born PGCs are CR+ and TH+ (De Marchis et al., 2007; Ninkovic et al., 2007). To compare the response of each PGC subtype to changes in olfactory input, we examined olfactoryinput-manipulated mice at various time points (Fig. 3A). First, to identify the subtype of PGCs whose apoptosis was promoted by naris occlusion (Fig. 2D), we stained $\mathrm{OB}$ sections of wild-type mice for ssDNA in combination with one of the PGC-subtypespecific markers. TH expression in dopaminergic (DAergic) PGCs was significantly decreased by the olfactory deprivation as previously reported (Baker et al., 1993), but still detectable even after 2 weeks of naris occlusion (data not shown). Significantly increased apoptosis was observed in the TH+ DAergic PGCs but not in the CB+ or CR+ PGCs (Fig. $3 B)(n=3$ animals; repeatedmeasure ANOVA followed by Tukey-Kramer test), indicating that the survival of the DAergic PGCs was particularly susceptible to olfactory deprivation. The number of PV + interneurons in the external plexiform layer, which lies next to the glomerular layer, was not affected by the 4 week naris occlusion (control, 11,680 \pm 1143 cells in the EPL; occlusion, 10,520 \pm 800 cells in the EPL; $n=3$ animals; $p>0.05$, paired $t$ test). Second, to identify the subtype of new PGCs whose survival was promoted by naris reopening (Fig. 2E), the number of BrdU-labeled new PGCs that expressed each PGC marker after naris reopening was compared with that in the occlusion condition in wild-type mice. Naris reopening significantly increased the number of $\mathrm{TH}+$ / BrdU+ new DAergic PGCs, but not of $\mathrm{CB}+/ \mathrm{BrdU}+$ or $\mathrm{CR}+/$ BrdU + new PGCs (Fig. $3 C)(n=4$ each for occlusion and reopening; repeated-measures ANOVA followed by TukeyKramer test). Although the increase in the number of $\mathrm{TH}+$ cells partly reflects the increased $\mathrm{TH}$ expression induced by naris reopening, these results suggest that the turnover of $\mathrm{TH}+\mathrm{DAergic}$ PGCs but not of $\mathrm{CB}+$ or CR + PGCs is regulated by olfactory experience.

To study the effects of olfactory manipulations on the survival of DAergic PGCs, we needed to label these cells stably regardless of their TH expression level. For this purpose, we used a genetic marker carried by TH-Cre;Rosa26R-CFP mice to trace cells of the DAergic lineage (Srinivas et al., 2001; Gong et al., 2007) (Fig. $3 D-M$, Table 1). In these mice, the mature DAergic PGCs continuously expressed CFP independent of TH promoter activity, and the expression of CFP was not affected by olfactory manipulations (Fig. $3 H-K$ ). On the other hand, it was possible that some new DAergic PGCs arrived during olfactory deprivation that did not express Cre until the naris was reopened. To test this possibility, BrdU was injected before naris occlusion, and CFP expres- 
A

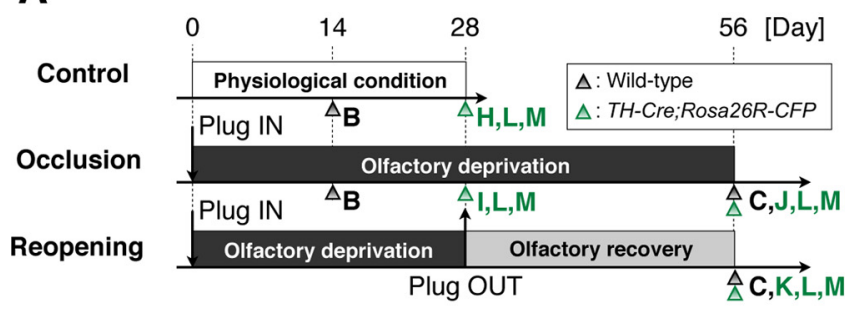

B

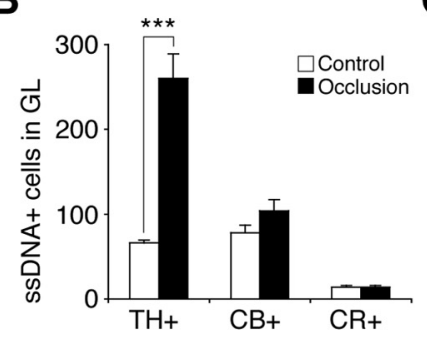

C

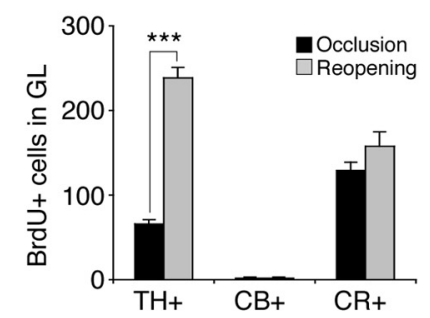

D
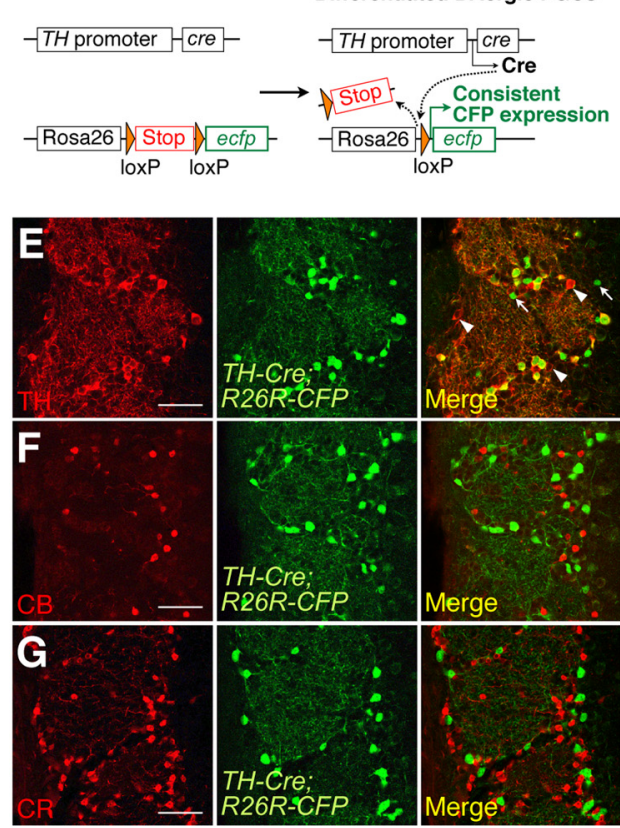
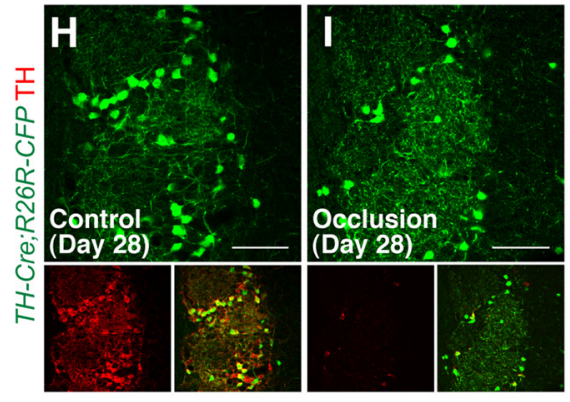

$\mathbf{L}$

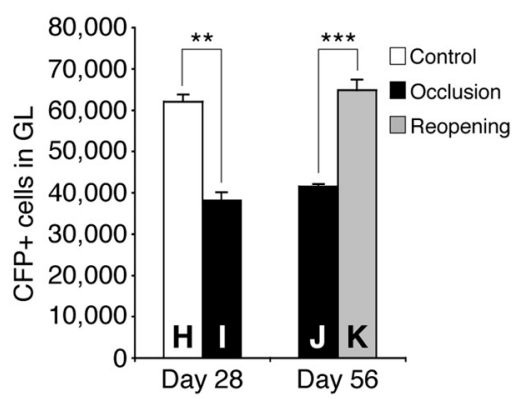

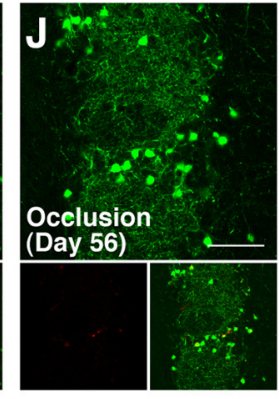

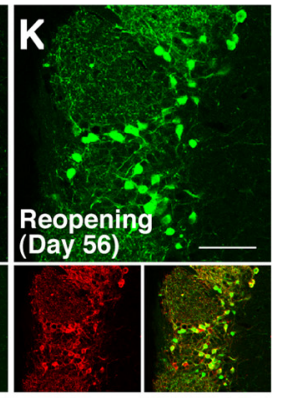

M

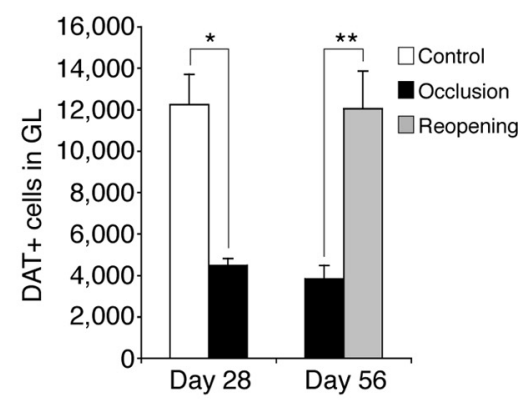

Figure 3. Olfactory-input-dependent regulation on the survival of DAergic subtype of PGCs. $A$, Experimental design. Bold letters indicate the time points of the analyses shown in $\boldsymbol{B}, \boldsymbol{C}$, and $\boldsymbol{H}-\boldsymbol{M}$. $B, C$, Apoptosis $(\boldsymbol{B})$ and the addition $(\boldsymbol{C})$ of PGCs of each subtype upon naris occlusion and reopening. Naris occlusion and reopening significantly increased the number of apoptotic (ssDNA + ) and newly added (BrdU+) TH+ DAergic PGCs, respectively, but not CB + or CR+PGCS $\left.*^{* *} p<0.000005\right)$. BrdU was injected on day 28 (C). D, Diagram of the Cre-mediated recombination in TH+ DAergic PGCs used in this study. E-G, Coronal sections of the olfactory glomerular layer in TH-Cre; Rosa26R-CFP mice stained for TH, CB, and CR (red). The majority of the CFP + PGCs (green) expressed TH. Only a small number of TH-/CFP+ PGCS and CFP-/TH + PGCs (white arrows and arrowheads, respectively) were observed (E). The CB+ and CR+PGCS never expressed CFP $(\boldsymbol{F}$ and $\boldsymbol{G}$, respectively). See also Table 1. H-M, Olfactory-input-dependent dynamic alterations in the number of DAergic PGCs. Coronal sections of the olfactory glomerular layer in $T H$-Cre;Rosa26R-CFP mice $(\boldsymbol{H}-\boldsymbol{K})$ stained for GFP (green) and TH (red). The merged image (bottom right) shows that almost all the CFP + DAergic PGCs also expressed TH in the control OB $(\boldsymbol{H})$. Although the TH expression in these cells was mostly abolished by naris occlusion (day $28, I$ and day $56, J$, red), these cells could be clearly detected by their stable and continuous (FP expression (green). The number of CFP + DAergic PGCs was significantly reduced by 4 week naris occlusion ( $L$, day $\left.28,{ }^{* *} p<0.01\right)$, and increased by naris reopening ( $L$, day $\left.56,{ }^{* * *} p<0.0005\right)$, to a level comparable to that of the control $O B(\boldsymbol{H})$. The number of DAT + DAergic PGCS was also decreased by the 4 week naris occlusion $\left(M\right.$, day $\left.28,{ }^{*} p<0.05\right)$ and increased by naris reopening $\left(M\right.$, day $\left.56,{ }^{* *} p<0.01\right) . S$ Sale bars: $50 \mu \mathrm{m}$. The data are presented as the mean \pm SEM.

sion was analyzed in the BrdU-labeled cells before and after naris reopening. Reopening the naris did not affect the survival of these $\mathrm{BrdU}+$ cells in the glomerular layer, nor did it alter the percentage of CFP+ PGCs in the BrdU+ cells (day 28, 7.1 $\pm 1.1 \%, n=$ 4 animals; day $56,6.2 \pm 0.8 \%, n=4$ animals; $p>0.05$, unpaired $t$ test), suggesting that these new DAergic PGCs expressed Cre and CFP without olfactory input, probably due to the promoter activity of the $T H$ gene in the adult RMS, reported previously (Saino-Saito et al., 2004).

Naris occlusion decreased the CFP-labeled (CFP+) DAergic PGCs to $60 \%$ of baseline (Fig. $3 H, I, L)(n=3$ animals; paired $t$ test), suggesting that the survival of DAergic PGCs is dependent on the olfactory input. Consistent with this finding, naris occlusion increased the cleaved caspase-3+ apoptotic cell death of CFP+ PGCs (control, $3.0 \pm 3.0$ cells in the GL; 2 week naris occlusion, $16.0 \pm 2.0$ cells in the GL; $n=3$ animals; $p=0.039$, paired $t$ test). On the other hand, the number of CFP+ DAergic
PGCs was increased by naris reopening (Fig. $3 J-L$ ) (occlusion, $n=3$ animals; reopening, $n=4$ animals; Mann-Whitney $U$ test). Consistently, on day 56, naris reopening significantly increased the number of BrdU+/CFP+ DAergic PGCs, which had incorporated BrdU on day 28 (occlusion, $18.7 \pm 3.5$ cells in the GL, $n=3$ animals; reopening, $102.7 \pm 8.4$ cells in the GL, $n=3$ animals; $p=0.00076$, unpaired $t$ test).

Since all the DAergic PGCs were not labeled in the TH-Cre; Rosa26R-CFP mice, the possibility remained that the turnover of the TH+/CFP - DAergic PGCs (35\% of TH+ DAergic PGCs) is not regulated by olfactory input. To test this possibility, we stained another marker for DAergic neurons, DAT, whose expression is not regulated by the TH gene promoter (Cave et al., 2010) and is detectable in $40 \%$ of the $\mathrm{TH}+/ \mathrm{CFP}-$ population. The number of DAT + DAergic PGCs was significantly decreased after a 4 week naris occlusion (Fig. $3 M$ ) (day $28 ; n=3$ animals; paired $t$ test) and increased to the control level 4 weeks after naris 
reopening (Fig. $3 M$ ) (day 56; $n=3$ each for occlusion and reopening; unpaired $t$ test), similar to the results of the CFP+ DAergic PGCs (Fig. 3L). Together, these findings indicate that turnover of DAergic PGCs is dynamically controlled by olfactory experience in a subtype-specific manner.

\section{Olfactory input recruits new DAergic PGCs into the positions of functional DAergic PGCs eliminated by two-photon laser ablation}

To study the turnover dynamics of the TH+ DAergic PGCs directly under 2PLSM, we used another transgenic mouse line, $T H$-GFP, which expresses GFP under the $T H$ gene promoter (Sawamoto et al., 2001; Matsushita et al., 2002) (Fig. 4A-D, Table $1)$. There were no significant differences in the numbers of the proliferating $(\mathrm{Ki} 67+)$ and apoptotic $(\mathrm{ssDNA}+)$ cells in the SVZ, RMS, or core of the OB between TH-GFP mice and VGAT-Venus mice (data not shown). The turnover ratio of DAergic PGCs (added population on days $0-28,12.6 \pm 1.4 \%$; lost population on days $0-28,8.9 \pm 0.8 \%$; added population on days $28-56$, $11.1 \pm 0.9 \%$; lost population on days $28-56,8.0 \pm 0.7 \% ; n=3$ animals) was significantly higher than that of the entire set of PGCs observed in the VGAT-Venus and GAD67-GFP mice (Fig. $4 D$, compared with Fig. $2 D, E$ ), indicating that this subtype of PGCs is intensively replaced under normal physiological conditions.

To investigate whether the empty positions were filled by new neurons (Fig. $2 F, G$ ) after the death of a small number of DAergic PGCs, the most actively cycling subtype (Figs. 3, 4D), we used in vivo two-photon laser ablation (Davalos et al., 2005) (Fig. 4E-K). The selective and complete elimination of the targeted PGCs (1-4 cells per glomerulus) was confirmed by "shadow imaging" (Kitamura et al., 2008) (see Materials and Methods), which allowed us to conclude that the disappearance of the GFP signal reflected the elimination of cell bodies ( $100 \pm 0 \% ; n=5$ animals $)$ and not transient bleaching (Fig. $4 F$ ). We found that these empty positions induced by laser ablation were more frequently filled with new PGCs than were the open spaces that occurred naturally from cell death (Fig. $4 E, G, K$ ) (control [ $n=3$ animals] and laser ablation $[n=5$ animals], respectively; unpaired $t$ test). While the "stable" PGCs showed an unchanging dendritic pattern throughout the experimental period (Mizrahi, 2007) (Fig. 4I, J, cells 4 and 6), the new "replacing" DAergic PGCs extended their dendrites in different directions from those of the previously eliminated ones (Fig. 4I,J, red and black asterisks) (100 $\pm 0 \% ; n=5$ animals).

We next performed the laser ablation of DAergic PGCs in mice fitted with a nasal occlusion plug. In TH-GFP mice, the expression of GFP as well as of TH was decreased after the 4 week naris occlusion and increased 4 weeks after naris reopening. However, by using a higher laser power, most $(>99 \%)$ of the GFP + DAergic PGCs identified on both day 0 (before the naris occlusion) and day 56 (after the reopening) could also be observed on day 28 (after the occlusion), indicating that even under the olfactory-deprivation conditions, GFP + cell bodies have detectable levels of fluorescence by 2PLSM (Fig. $4 H$, day 28). Next, we examined whether the empty positions made by laser ablation were filled by new DAergic PGCs after a 4 week naris occlusion. We found that the naris occlusion significantly decreased the frequency of PGC recruitment to these empty positions (Fig. $4 H, K)$ (laser ablation $[n=5$ animals] and laser ablation and occlusion [ $n=4$ animals], respectively; Mann-Whitney $U$ test). Considering all of these results, we conclude that olfactory input promotes the reiterated use of the same positions in glomeruli by new DAergic PGCs.

\section{Discussion}

In this work, we studied the mechanisms of PGC turnover directly in vivo. The dynamics, subtype specificity, and spatial characteristics of the added and lost PGCs observed in the live OB demonstrate novel olfactory-input-dependent mechanisms of neuronal replacement in the adult $\mathrm{OB}$.

In our 2PLSM experiments, we observed the turnover dynamics of the entire PGC population using several reporter mice, in which almost all the PGCs were labeled. Although the reporter mice expressed the fluorescent protein in some immature migratory precursors in addition to mature neurons with stable primary dendrites (Fig. $4 I, J$ ), only $4 \%$ of the "lost" population can be accounted for by migrating PGCs; most (>90\%) of the "lost" cells represented mature PGCs that had died. In addition, $96 \%$ of the "added" PGCs identified on day 28 were still present on day 56 , suggesting that they matured in situ, and were not transient.

Based on the results obtained with VGAT-Venus mice, in which almost all the PGCs are labeled, we determined that the turnover ratio of PGCs is $\sim 10 \%$ per month ( $6 \%$ addition and $4 \%$ loss), which is considerably higher than previously reported (3\% per month) (Mizrahi et al., 2006). This difference could be due to the different labeling efficiencies of the reporter mice used in these studies. Other studies using long-term genetic fatemapping of neural stem cells in the SVZ estimated that the percentage of neuronal addition in the glomerular layer is 3-4\% per month (Lagace et al., 2007; Ninkovic et al., 2007). The slight differences between these studies and ours might be attributable to the amount of unlabeled $\mathrm{Dcx}+$ population and the lineage characteristics (i.e., GCs vs PGCs) of GLAST + or Nestin + cells in the SVZ. Despite the active addition of PGCs, the glomerular structure and volume is stable during aging (Richard et al., 2010), indicating that the balance between the addition and elimination of the PGCs is regulated throughout the life span.

We found that the three PGC subtypes showed distinct responses to the olfactory experience (Figs. 2, 3). Recent studies reported that naris occlusion reduces the number of newly generated TH+ DAergic PGCs but not $\mathrm{CB}+$ or CR + PGCs (Bovetti et al., 2009; Bastien-Dionne et al., 2010), suggesting that only DAergic PGCs depend on olfactory input for their survival. However, since TH expression itself is dependent on olfactory input (Baker et al., 1993), conventional TH-immunostaining did not allow the counting of an accurate number of DAergic PGCs after naris occlusion/reopening. Using genetic tracing of the DAergic lineage in the TH-Cre;Rosa26R-CFP mice, we clearly demonstrated that the survival of DAergic PGCs is decreased by naris occlusion and recovered by the reopening. Since dopamine, which is secreted by DAergic PGCs, is involved in the presynaptic inhibition of olfactory sensory neurons (Hsia et al., 1999), it is possible that the olfactory-input-regulated turnover of DAergic PGCs modulates the strength of olfactory stimuli transmitted to the higher olfactory center.

In addition to the plastic aspect of glomerular circuits revealed by the dynamics of the olfactory-experience-dependent turnover of DAergic PGCs (Figs. 2, 3), this study has demonstrated a mechanism that contributes to their structural stability (Figs. 2, 4). Using in vivo three-time-point imaging, we found that olfactory input promotes the reiterated use of the same positions in the glomeruli by new PGCs (Fig. 2G). Moreover, the positions that had lost functional DAergic PGCs by in vivo two-photon laser ablation recruited the same subtype in an olfactory-inputdependent manner (Fig. $4 \mathrm{~K}$ ). The naris occlusion condition in the laser-ablation experiment might have affected not only the 

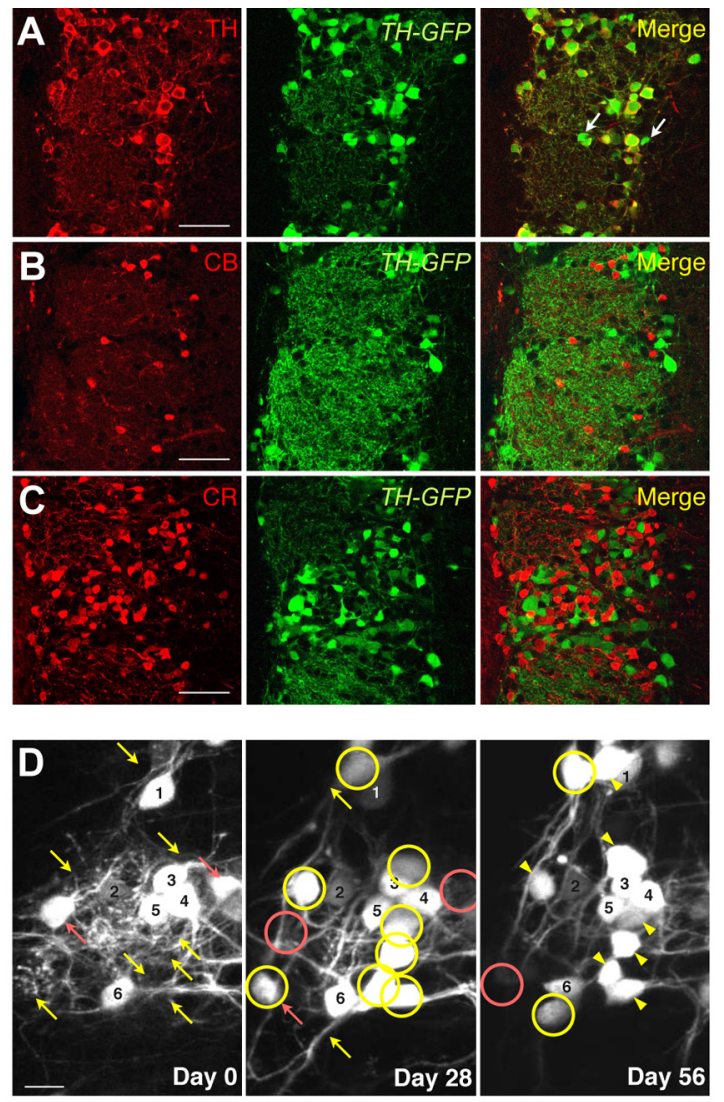

Series of optical sections $(2-\mu \mathrm{m}$ intervals $)$
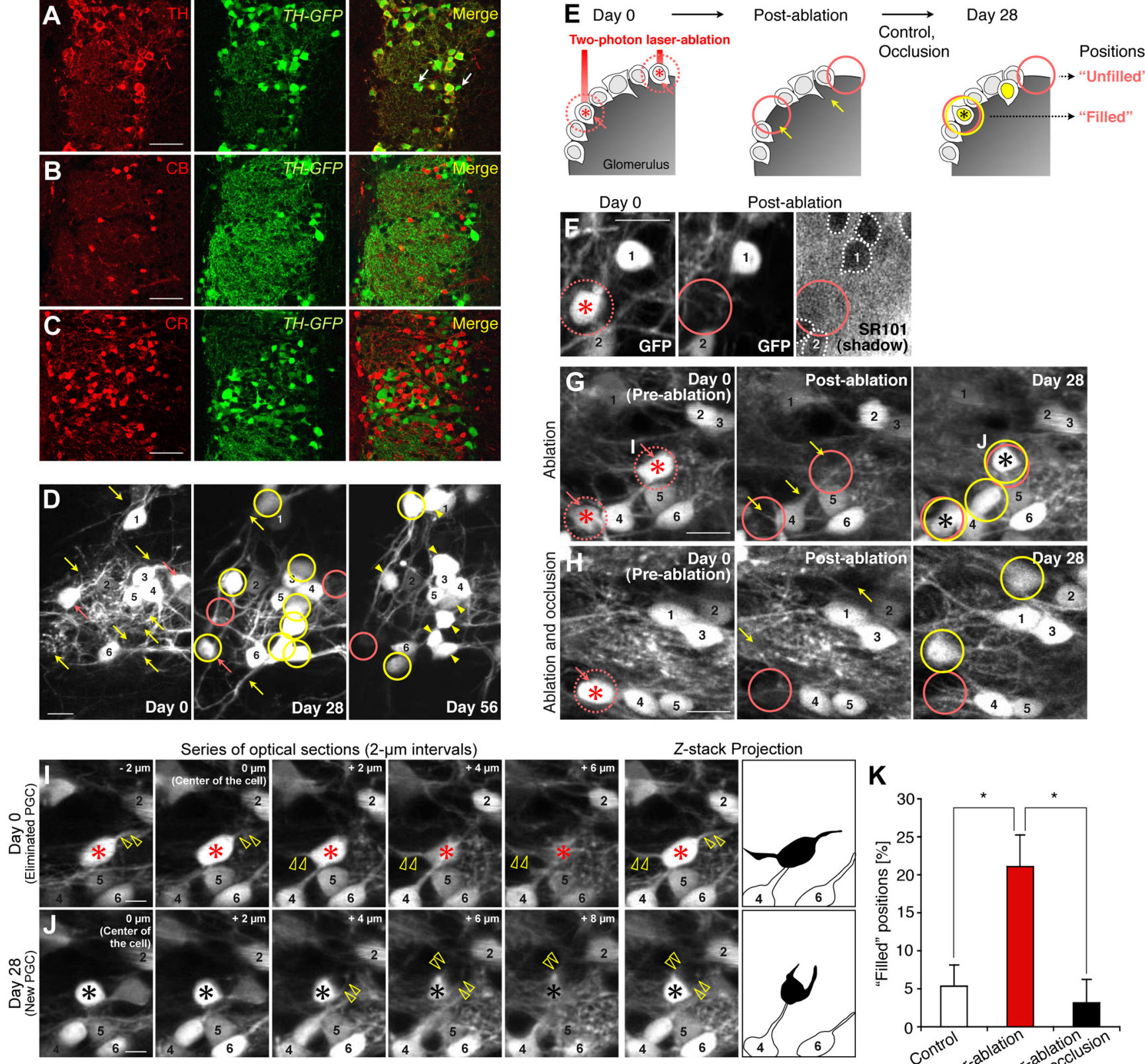

Z-stack Projection
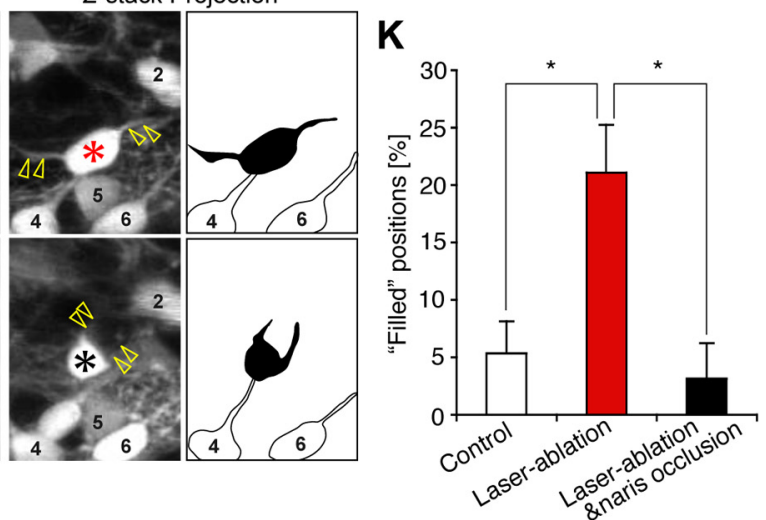

Figure 4. Olfactory-input-dependent recruitment of new DAergic PGCs into the positions of functional DAergic PGCs eliminated by laser ablation. $\boldsymbol{A}-\boldsymbol{C}$, GFP-expression pattern in the olfactory glomerular layer of TH-GFP mice. Coronal sections of the glomerular layer were stained for TH, CB, and CR $(\boldsymbol{A}-\boldsymbol{C}$, red). All of the TH+ PGCS $(\boldsymbol{A})$, but none of the $C B+$ or $C R+P G C s(B$ and $\boldsymbol{C}$, respectively) were labeled with GFP (green). A portion of the GFP + PGCs did not express TH ( $\boldsymbol{A}$, white arrows). See also Table $1 . \boldsymbol{D}$, In vivo repeated imaging of GFP + PGCs in $T H$-GFP mice. Sequential images on days 0,28 , and 56 clearly show the stable (numbered), lost (pink arrows and circles), and added (yellow arrows and circles) PGCs in this area. $\boldsymbol{E}$, Classification of the positions that had lost PGCs by laser ablation. PGCs labeled with a red asterisk were eliminated by laser ablation $(\boldsymbol{E}-\boldsymbol{J})$. Positions filled by new PG(s on day 28 are indicated by a black asterisk ( $\boldsymbol{E}, \boldsymbol{G}, \boldsymbol{J})$. $\boldsymbol{F}-\boldsymbol{H}$, Representative in vivo images showing the positions that had lost PGCs by laser ablation in TH-GFP mice. There was no SR101-negative "shadow" (white dashed circle) at the site of the ablated PGCs (F). Note that positions filled by new PGCs (black asterisks) were observed in the ablation group $(\boldsymbol{G})$ but not in the ablation and occlusion group $(\boldsymbol{H})$ in these areas (day 28 ). Single optical sections and their $z$-stack projection images of two PGCs in $\mathbf{G}$ are shown in $\mathbf{I}$ and $\boldsymbol{J}$. I, J, Analysis of the dendrites of the eliminated DAergic PGCs and the newly added ones at the same positions. Series of single optical sections at $2 \mu \mathrm{m}$ intervals ( $\mu \mathrm{m}$ : $z$-axis distance from the center of the PGC) and z-stack projection images showed that the eliminated and new DAergic PGCs extended their primary dendrites in distinct directions (Z-stack Projection, black shadows). In contrast, PGCs observed to be stable (cell 4 and 6) did not change their dendritic direction throughout the imaging period. The yellow open arrowheads indicate the primary dendrites of targeted DAergic PGCS. K, Quantification of the positions filled by new PGCs on day 28 . The percentage of filled positions in the ablation group (red) was significantly greater than in the control group (white) $\left({ }^{*} p<0.05\right)$, and the increase was suppressed by a 4 week naris occlusion (black) $\left({ }^{*} p<0.05\right)$. The pink circles indicate the territory of lost $P G C s$ $(\boldsymbol{D}-\boldsymbol{H})$. Numbers in $\boldsymbol{F}-\boldsymbol{J}$ indicate PGCs that were consistently observed throughout the experimental period. Scale bars: $\boldsymbol{A}-\boldsymbol{C}, 50 \mu \mathrm{m}, \boldsymbol{D}, \boldsymbol{F}-\boldsymbol{H}, 10 \mu \mathrm{m} ; \boldsymbol{I}, \boldsymbol{J}, 5 \mu \mathrm{m}$. The data are presented as the mean \pm SEM.

replacement events for the ablated positions but also the populations of lost and replaced cells. However, since the empty positions created by naris occlusion captured few newcomers (Fig. $2 G$ ), it is unlikely that their presence affected the analysis of the filled laser-ablated positions. Although the added cell population was decreased by naris occlusion, this decrease alone does not explain the drastic reduction in the percentage of filled laserablated positions (Fig. $4 K$ ). Based on these results, we conclude 
that new PGCs are recruited into empty positions in an olfactoryinput-dependent manner.

We found that neuronal addition in the adult $\mathrm{OB}$ was regulated spatiotemporally by olfactory input. However, the molecular mechanisms of this turnover pattern remain to be elucidated. It is possible that astrocytes, microglia, pericytes, and/or vascular endothelial cells surrounding the positions to be filled by new neurons release attractive factors that recruit new PGCs. Alternatively, newcomers arriving at the empty positions by chance may continuously receive neurotrophic factors from the surrounding cells that promote their survival. In addition, the electrical activities of neighboring PGCs, which are directly affected by olfactory input, may support the survival of new PGCs. Understanding whether the PGCs added at the empty positions are recruited as part of a targeting mechanism or arrive stochastically will provide new insights into the processes controlling neuronal turnover in the adult brain.

It has been reported that new PGCs extend stable primary dendrites (Mizrahi, 2007). The directions of the primary dendrites of the "replacing" new DAergic PGCs were different from those of the eliminated ones (Fig. $4 I, J$ ), suggesting that the activity-dependent reiterated use of positions for added DAergic PGCs could contribute to the maintenance of the cellular composition, but not of the dendritic field. Because the spherical glomerular structure shows robustness throughout the life span (Richard et al., 2010), our finding could represent a mechanism to maintain structural stability in the adult brain by adding new neurons (Prosser et al., 2007; Imayoshi et al., 2008). Under physiological conditions, most of the new PGCs were added independently of the positions that had lost PGCs. In addition to the synaptic turnover and movement of dendritic tips (Mizrahi, 2007; Livneh et al., 2009), the PGC addition pattern in the glomeruli could be plastic. In conclusion, this study suggests that the olfactory-input-dependent mechanisms of PGC turnover control the balance between the structural plasticity and stability of glomeruli, thereby enabling active remodeling of the neuronal circuitry and maintenance of the glomerular structure, depending on the olfactory input.

\section{References}

Altman J (1969) Autoradiographic and histological studies of postnatal neurogenesis. IV. Cell proliferation and migration in the anterior forebrain, with special reference to persisting neurogenesis in the olfactory bulb. J Comp Neurol 137:433-457.

Alvarez-Buylla A, Lim DA (2004) For the long run: maintaining germinal niches in the adult brain. Neuron 41:683-686.

Baker H, Morel K, Stone DM, Maruniak JA (1993) Adult naris closure profoundly reduces tyrosine hydroxylase expression in mouse olfactory bulb. Brain Res 614:109-116.

Bastien-Dionne PO, David LS, Parent A, Saghatelyan A (2010) Role of sensory activity on chemospecific populations of interneurons in the adult olfactory bulb. J Comp Neurol 518:1847-1861.

Bovetti S, Veyrac A, Peretto P, Fasolo A, De Marchis S (2009) Olfactory enrichment influences adult neurogenesis modulating GAD67 and plasticity-related molecules expression in newborn cells of the olfactory bulb. PLoS One 4:e6359.

Breton-Provencher V, Lemasson M, Peralta MR 3rd, Saghatelyan A (2009) Interneurons produced in adulthood are required for the normal functioning of the olfactory bulb network and for the execution of selected olfactory behaviors. J Neurosci 29:15245-15257.

Cave JW, Akiba Y, Banerjee K, Bhosle S, Berlin R, Baker H (2010) Differential regulation of dopaminergic gene expression by Er81. J Neurosci 30:4717-4724.

Cummings DM, Henning HE, Brunjes PC (1997) Olfactory bulb recovery after early sensory deprivation. J Neurosci 17:7433-7440.

Davalos D, Grutzendler J, Yang G, Kim JV, Zuo Y, Jung S, Littman DR, Dustin
ML, Gan WB (2005) ATP mediates rapid microglial response to local brain injury in vivo. Nat Neurosci 8:752-758.

De Marchis S, Bovetti S, Carletti B, Hsieh YC, Garzotto D, Peretto P, Fasolo A, Puche AC, Rossi F (2007) Generation of distinct types of periglomerular olfactory bulb interneurons during development and in adult mice: implication for intrinsic properties of the subventricular zone progenitor population. J Neurosci 27:657-664.

Denk W, Strickler JH, Webb WW (1990) Two-photon laser scanning fluorescence microscopy. Science 248:73-76.

Gheusi G, Cremer H, McLean H, Chazal G, Vincent JD, Lledo PM (2000) Importance of newly generated neurons in the adult olfactory bulb for odor discrimination. Proc Natl Acad Sci U S A 97:1823-1828.

Gong S, Doughty M, Harbaugh CR, Cummins A, Hatten ME, Heintz N, Gerfen CR (2007) Targeting Cre recombinase to specific neuron populations with bacterial artificial chromosome constructs. J Neurosci 27:9817-9823.

Haba H, Nomura T, Suto F, Osumi N (2009) Subtype-specific reduction of olfactory bulb interneurons in Pax6 heterozygous mutant mice. Neurosci Res 65:116-121.

Hack MA, Saghatelyan A, de Chevigny A, Pfeifer A, Ashery-Padan R, Lledo PM, Götz M (2005) Neuronal fate determinants of adult olfactory bulb neurogenesis. Nat Neurosci 8:865-872.

Holtmaat A, Wilbrecht L, Knott GW, Welker E, Svoboda K (2006) Experiencedependent and cell-type-specific spine growth in the neocortex. Nature 441:979-983.

Hsia AY, Vincent JD, Lledo PM (1999) Dopamine depresses synaptic inputs into the olfactory bulb. J Neurophysiol 82:1082-1085.

Imayoshi I, Sakamoto M, Ohtsuka T, Takao K, Miyakawa T, Yamaguchi M, Mori K, Ikeda T, Itohara S, Kageyama R (2008) Roles of continuous neurogenesis in the structural and functional integrity of the adult forebrain. Nat Neurosci 11:1153-1161.

Kaneko N, Marín O, Koike M, Hirota Y, Uchiyama Y, Wu JY, Lu Q, TessierLavigne M, Alvarez-Buylla A, Okano H, Rubenstein JL, Sawamoto K (2010) New neurons clear the path of astrocytic processes for their rapid migration in the adult brain. Neuron 67:213-223.

Kitamura K, Judkewitz B, Kano M, Denk W, Häusser M (2008) Targeted patch-clamp recordings and single-cell electroporation of unlabeled neurons in vivo. Nat Methods 5:61-67.

Kohwi M, Osumi N, Rubenstein JL, Alvarez-Buylla A (2005) Pax6 is required for making specific subpopulations of granule and periglomerular neurons in the olfactory bulb. J Neurosci 25:6997-7003.

Kosaka K, Kosaka T (2007) Chemical properties of type 1 and type 2 periglomerular cells in the mouse olfactory bulb are different from those in the rat olfactory bulb. Brain Res 1167:42-55.

Lagace DC, Whitman MC, Noonan MA, Ables JL, DeCarolis NA, Arguello AA, Donovan MH, Fischer SJ, Farnbauch LA, Beech RD, DiLeone RJ, Greer CA, Mandyam CD, Eisch AJ (2007) Dynamic contribution of nestin-expressing stem cells to adult neurogenesis. J Neurosci 27:12623-12629.

Livneh Y, Feinstein N, Klein M, Mizrahi A (2009) Sensory input enhances synaptogenesis of adult-born neurons. J Neurosci 29:86-97.

Lledo PM, Saghatelyan A (2005) Integrating new neurons into the adult olfactory bulb: joining the network, life-death decisions, and the effects of sensory experience. Trends Neurosci 28:248-254.

Lledo PM, Alonso M, Grubb MS (2006) Adult neurogenesis and functional plasticity in neuronal circuits. Nat Rev Neurosci 7:179-193.

Lois C, Alvarez-Buylla A (1994) Long-distance neuronal migration in the adult mammalian brain. Science 264:1145-1148.

Luskin MB (1993) Restricted proliferation and migration of postnatally generated neurons derived from the forebrain subventricular zone. Neuron 11:173-189.

Mak GK, Enwere EK, Gregg C, Pakarainen T, Poutanen M, Huhtaniemi I, Weiss S (2007) Male pheromone-stimulated neurogenesis in the adult female brain: possible role in mating behavior. Nat Neurosci 10:1003-1011.

Matsushita N, Okada H, Yasoshima Y, Takahashi K, Kiuchi K, Kobayashi K (2002) Dynamics of tyrosine hydroxylase promoter activity during midbrain dopaminergic neuron development. J Neurochem 82:295-304.

Mizrahi A (2007) Dendritic development and plasticity of adult-born neurons in the mouse olfactory bulb. Nat Neurosci 10:444-452. 
Mizrahi A, Lu J, Irving R, Feng G, Katz LC (2006) In vivo imaging of juxtaglomerular neuron turnover in the mouse olfactory bulb. Proc Natl Acad Sci U S A 103:1912-1917.

Moreno MM, Linster C, Escanilla O, Sacquet J, Didier A, Mandairon N (2009) Olfactory perceptual learning requires adult neurogenesis. Proc Natl Acad Sci U S A 106:17980-17985.

Ninkovic J, Mori T, Götz M (2007) Distinct modes of neuron addition in adult mouse neurogenesis. J Neurosci 27:10906-10911.

Petreanu L, Alvarez-Buylla A (2002) Maturation and death of adult-born olfactory bulb granule neurons: role of olfaction. J Neurosci 22:6106-6113.

Prosser HM, Bradley A, Caldwell MA (2007) Olfactory bulb hypoplasia in Prokr2 null mice stems from defective neuronal progenitor migration and differentiation. Eur J Neurosci 26:3339-3344.

Richard MB, Taylor SR, Greer CA (2010) Age-induced disruption of selective olfactory bulb synaptic circuits. Proc Natl Acad Sci U S A 107:15613-15618.

Rochefort C, Gheusi G, Vincent JD, Lledo PM (2002) Enriched odor exposure increases the number of newborn neurons in the adult olfactory bulb and improves odor memory. J Neurosci 22:2679-2689.

Saino-Saito S, Sasaki H, Volpe BT, Kobayashi K, Berlin R, Baker H (2004) Differentiation of the dopaminergic phenotype in the olfactory system of neonatal and adult mice. J Comp Neurol 479:389-398.

Sawamoto K, Nakao N, Kobayashi K, Matsushita N, Takahashi H, Kakishita K, Yamamoto A, Yoshizaki T, Terashima T, Murakami F, Itakura T, Okano H (2001) Visualization, direct isolation, and transplantation of midbrain dopaminergic neurons. Proc Natl Acad Sci U S A 98:6423-6428.

Sawamoto K, Wichterle H, Gonzalez-Perez O, Cholfin JA, Yamada M, Spassky N, Murcia NS, Garcia-Verdugo JM, Marin O, Rubenstein JL, Tessier-Lavigne
M, Okano H, Alvarez-Buylla A (2006) New neurons follow the flow of cerebrospinal fluid in the adult brain. Science 311:629-632.

Srinivas S, Watanabe T, Lin CS, William CM, Tanabe Y, Jessell TM, Costantini F (2001) Cre reporter strains produced by targeted insertion of EYFP and ECFP into the ROSA26 locus. BMC Dev Biol 1:4.

Tamamaki N, Yanagawa Y, Tomioka R, Miyazaki J, Obata K, Kaneko T (2003) Green fluorescent protein expression and colocalization with calretinin, parvalbumin, and somatostatin in the GAD67-GFP knock-in mouse. J Comp Neurol 467:60-79.

Trachtenberg JT, Chen BE, Knott GW, Feng G, Sanes JR, Welker E, Svoboda K (2002) Long-term in vivo imaging of experience-dependent synaptic plasticity in adult cortex. Nature 420:788-794.

Wake H, Moorhouse AJ, Jinno S, Kohsaka S, Nabekura J (2009) Resting microglia directly monitor the functional state of synapses in vivo and determine the fate of ischemic terminals. J Neurosci 29:3974-3980.

Wang Y, Kakizaki T, Sakagami H, Saito K, Ebihara S, Kato M, Hirabayashi M, Saito Y, Furuya N, Yanagawa Y (2009) Fluorescent labeling of both GABAergic and glycinergic neurons in vesicular GABA transporter (VGAT)-venus transgenic mouse. Neuroscience 164:1031-1043.

Xu HT, Pan F, Yang G, Gan WB (2007) Choice of cranial window type for in vivo imaging affects dendritic spine turnover in the cortex. Nat Neurosci 10:549-551.

Yamaguchi M, Mori K (2005) Critical period for sensory experiencedependent survival of newly generated granule cells in the adult mouse olfactory bulb. Proc Natl Acad Sci U S A 102:9697-9702.

Yang G, Pan F, Gan WB (2009) Stably maintained dendritic spines are associated with lifelong memories. Nature 462:920-924.

Zhao C, Deng W, Gage FH (2008) Mechanisms and functional implications of adult neurogenesis. Cell 132:645-660. 